\title{
Red blood cell transfusion may be more detrimental than anemia for the clinical outcome of patients with severe traumatic brain injury
}

\author{
Santiago R. Leal-Noval ${ }^{1 *}$, María D. Rincón-Ferrari ${ }^{1}$ and Manuel Múñoz-Gómez² \\ This comment refers to the article available at https://doi.org/10.1186/s13054-018-2273-9
}

To the Editor,

Gobatto et al. [1] have published a RCT in the Journal comparing a restrictive red blood cell transfusion (RBCT) strategy (hemoglobin threshold $7 \mathrm{~g} / \mathrm{dL} ; N=23$ ) with a liberal strategy (hemoglobin $9 \mathrm{~g} / \mathrm{dL} ; N=21$ ) in ICU patients sustaining severe traumatic brain injury (TBI). When compared with the liberal RBCT group, the restrictive RBCT group had lower 14-day hemoglobin concentration (8.4 \pm $1.0 \mathrm{~g} / \mathrm{dL}$ vs. $9.3 \pm 1.3 \mathrm{~g} / \mathrm{dL}$, respectively; $p<0.01$ ) (primary objective) and higher in-hospital mortality (30 vs. $5 \%$, respectively; $p=0.05$ ), as well as a trend toward worsen neurological status, as assessed by unfavorable Glasgow Outcome Scale (GOS) both at discharge and 6 months after hospital discharge ( $48 \%$ vs $38 \%$, respectively; $p=0.20$ ) (secondary objectives). Though the authors consider their secondary outcome analysis as exploratory, they stated that their data were in line with previous publications pointing toward the superiority of the liberal transfusion strategy. Several study limitations were acknowledged, mainly that, at baseline, the restrictive group would be more severely affected than the liberal group, and this could explain part of the reported secondary outcomes [1].

Notwithstanding this, we would like to point out that (1) the mean of the difference between both groups was only $0.9 \mathrm{~g} / \mathrm{dL}$, but the sample size was calculated to detect a mean difference of $1.2 \mathrm{~g} / \mathrm{dL}$. It seems hardly probable that a hemoglobin difference $<1 \mathrm{~g} / \mathrm{dL}$ may influence the clinical outcome; (2) the total number of RBC units transfused over the length of hospital stay (pre- and post-randomization) was finally higher in the restrictive group (164 U; $7.1 \mathrm{U} /$ patient) than that in the liberal group (131 U; $6.2 \mathrm{U} /$ patient); (3) the authors speculate that cerebral oxygenation, which was not measured in this RCT, could have been impaired in the restrictive arm, thus explaining the poorer clinical outcome in this group. Assessment of cerebral oxygenation may lead to more efficient RBCT. In a recent RCT [2], we explored the reliability of a NIRS threshold-based protocol for RBCT in a mixed population of moderately anemic, neurocritical patients. Compared with the sole use of a predefined hemoglobin threshold, a NIRS threshold resulted in decreased number of transfused patients (from 71 to 59\%; RR 0.83 [95\% CI 0.62-1.11]) and transfused units (from $1.5 \pm 1.4$ to $1.0 \pm 0.1 ; p<0.05$ ), with no differences in the incidence of adverse effects reported during 1-year follow-up. Finally, (4) in a 1-year follow-up study of 309 patients with TBI, we found an independent association between RBCT and unfavorable long-term neurocognitive outcome, suggesting that RBCT may exert a more detrimental effect than anemia [3]. In fact, recent guidelines continue recommending the adoption of a restrictive RBCT strategy $[4,5]$. Therefore, pending on confirmation by a larger trial, Gobatto et al.'s study results should be interpreted cautiously.

\footnotetext{
* Correspondence: srlealnoval@gmail.com

${ }^{1}$ Critical Care Division, University Hospital 'Virgen del Rocío', Unidad de

Cuidados Intensivos, $1^{a}$ planta, Avda Manuel Siurot s/n, 41013 Seville, Spain

Full list of author information is available at the end of the article
} 


\section{Authors' response}

\section{André L. N. Gobatto, Milena A. Link and Luiz M. S. Malbouisson}

We have read with great interest the letter from Dr. Leal-Noval et al. regarding our paper. They raise several questions we are pleased to provide answers.

In the TRAHT study [1], the mean hemoglobin concentration during the first 14 days after hospital admission was $9.3 \pm 1.3 \mathrm{~g} / \mathrm{dL}$ in the liberal group and $8.4 \pm 1.0$ $\mathrm{g} / \mathrm{dL}$ in the restrictive group $(p<0.01)$, giving a mean difference of $0.9 \pm 0.2 \mathrm{~g} / \mathrm{dL}$. It represents the mean difference in the 14 days' time point, meaning the difference on a daily basis was higher, especially in the first days after randomization. For example, the mean hemoglobin concentration difference on the 10th day was $1.8 \pm 0.4 \mathrm{~g} /$ $\mathrm{dL}(95 \%$ CI 1.0-2.6, $p<0.01)$ between liberal and restrictive groups. Furthermore, other randomized controlled trials evaluating two transfusion strategies based on hemoglobin triggers in different populations have found similar hemoglobin differences [6].

The TRAHT study was a randomized clinical trial, meaning the only difference between groups after randomization was the transfusion strategy. After randomization, the patients in the liberal group receive a total of 66 red blood cells (RBCs) units as compared with $35 \mathrm{RBC}$ units in the restrictive group $(p=0.02)$, with a good protocol adherence. However, the sample size was small, which may have led to unbalanced groups. The restrictive group had more pupil alterations and more midline deviation $\geq 5 \mathrm{~mm}$ on brain $\mathrm{CT}$, and more patients received blood transfusions before randomization compared to the liberal group 9 (43\%) vs. 15 (65\%), respectively. Nevertheless, the study groups were statistically well matched at baseline with respect to demographic and clinical characteristics. Although not statistically significant, it might suggest that the restrictive group would be more severely injured than the liberal group and this could explain part of the reported secondary outcomes.

Several experimental, physiological, and observational data point toward an increase in the brain tissue oxygen partial pressure $(\mathrm{PbtO} 2)$ in anemic neurocritical patients that received RBC transfusion [7]. If these results translate into better patient-centered outcomes, whether $\mathrm{PbtO} 2$ could be used to identify the patients which benefit from RBC transfusion remains to be determined.

Anemia as well as RBC transfusion is associated with worse outcomes in TBI patients $[8,9]$. However, these data come from observational trials which are deeply susceptible to confusion bias, even after statistical analysis of the data and are particularly influenced by the patients' severity. The most severe TBI patients are anemic, and the most severe anemic
TBI patients receive blood transfusion. Thus, TBI patients receiving blood transfusion would be always associated with worse outcomes in this setting. Therefore, only an adequately powered randomized clinical trial could answer the question if a strategy aimed at correcting anemia by RBC transfusion could benefit severe TBI patients. TRAHT was a pilot trial, aimed at evaluating the feasibility of a randomized clinical trial comparing liberal and restrictive blood transfusion strategies in patients with moderate and severe TBI. Although its secondary analysis in favor of the liberal transfusion strategy was noteworthy, we agree that the study results should be interpreted cautiously.

\section{Acknowledgements}

Not applicable.

Funding

Not funding.

Availability of data and materials

Not applicable.

Authors' contributions

All of the authors have significantly contributed to the conception and

design of the letter and approved the final version submitted for publication.

Ethics approval and consent to participate

Not applicable. This letter to Editor does not include patients.

Consent for publication

Yes, we consent for publication.

Competing interests

The authors declare that they have no competing interests.

\section{Publisher's Note}

Springer Nature remains neutral with regard to jurisdictional claims in published maps and institutional affiliations.

\section{Author details}

${ }^{1}$ Critical Care Division, University Hospital 'Virgen del Rocío', Unidad de Cuidados Intensivos, 1a planta, Avda Manuel Siurot s/n, 41013 Seville, Spain. ${ }^{2}$ Department of Surgical Specialties, Biochemistry and Immunology, School of Medicine, University of Málaga, campus de Teatinos s/n, 29010 Málaga, Spain

Received: 4 April 2019 Accepted: 10 May 2019

Published online: 27 May 2019

\section{References}

1. Gobatto ALN, Link MA, Solla DJ, Bassi E, Tierno PF, Paiva W, et al. Transfusion requirements after head trauma: a randomized feasibility controlled trial. Crit Care. 2019;23:89.

2. Leal-Noval SR, Muñoz-Serrano A, Arellano-Orden V, et al. Effects of red blood cell transfusion on long-term disability of patients with traumatic brain injury. Neurocrit Care. 2016;24:371-80.

3. Leal-Noval SR, Arellano-Orden V, Muñoz-Gómez M, et al. Red blood cell transfusion guided by near infrared spectroscopy in neurocritically ill 
patients with moderate or severe anemia: A randomized, controlled trial. J Neurotrauma. 2017;34:2553-9.

4. González de Molina Ortiz FJ, Gordo Vidal F, Estella García A, Morrondo Valdeolmillos P, Fernández Ortega JF, Caballero López J, et al. "Do not do" recommendations of the working groups of the Spanish Society of Intensive Care Medicine and Coronary Units (SEMICYUC) for the management of critically ill patients. Med Intensiva. 2018;42:425-43.

5. González-Pérez A, Al-Sibai JZ, Alvárez-Fernández P, Martínez-Cablor P, Argüello-Junquera M, García-Gala JM, et al. Liberal red blood cell transfusions impair quality of life after cardiac surgery. Med Intensiva. 2019; 43:156-64.

6. Villanueva C, Colomo A, Bosch A, Concepcion M, Hernandez-Gea V, Aracil C, Graupera I, Poca M, Alvarez-Urturi C, Gordillo J, et al. Transfusion strategies for acute upper gastrointestinal bleeding. N Engl J Med. 2013;368(1):11-21.

7. Zygun DA, Nortje J, Hutchinson PJ, Timofeev I, Menon DK, Gupta AK. The effect of red blood cell transfusion on cerebral oxygenation and metabolism after severe traumatic brain injury. Crit Care Med. 2009;37(3): $1074-8$.

8. Van Beek JG, Mushkudiani NA, Steyerberg EW, Butcher I, McHugh GS, Lu J, Marmarou A, Murray GD, Maas Al. Prognostic value of admission laboratory parameters in traumatic brain injury: results from the IMPACT study. J Neurotrauma. 2007;24(2):315-28.

9. Salim A, Hadjizacharia P, DuBose J, Brown C, Inaba K, Chan L, Margulies DR. Role of anemia in traumatic brain injury. J Am Coll Surg. 2008; 207(3):398-406. 